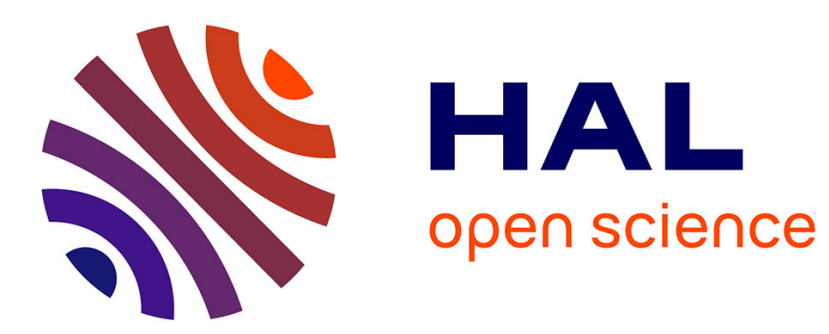

\title{
Physical interpretation of the Mullins softening in a carbon-black filled SBR
}

\author{
Rodrigo Diaz, Julie Diani, Pierre Gilormini
}

\section{To cite this version:}

Rodrigo Diaz, Julie Diani, Pierre Gilormini. Physical interpretation of the Mullins softening in a carbon-black filled SBR. Polymer, 2014, 55, pp.4942-4947. 10.1016/j.polymer.2014.08.020 . hal01061054

\section{HAL Id: hal-01061054 \\ https://hal.science/hal-01061054}

Submitted on 5 Sep 2014

HAL is a multi-disciplinary open access archive for the deposit and dissemination of scientific research documents, whether they are published or not. The documents may come from teaching and research institutions in France or abroad, or from public or private research centers.
L'archive ouverte pluridisciplinaire HAL, est destinée au dépôt et à la diffusion de documents scientifiques de niveau recherche, publiés ou non, émanant des établissements d'enseignement et de recherche français ou étrangers, des laboratoires publics ou privés. 


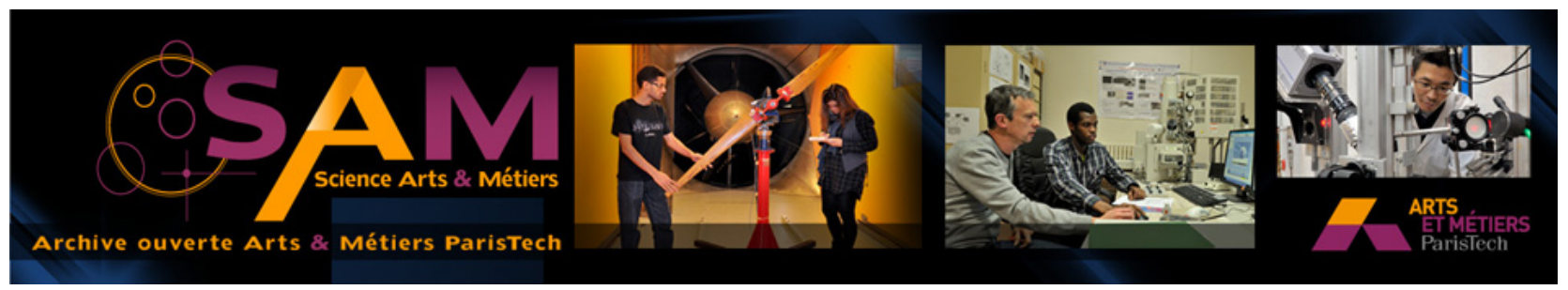

Science Arts \& Métiers (SAM)

is an open access repository that collects the work of Arts et Métiers ParisTech researchers and makes it freely available over the web where possible.

This is an author-deposited version published in: http://sam.ensam.eu Handle ID: .http://hdl.handle.net/10985/8457

\section{To cite this version :}

Rodrigo DIAZ, Julie DIANI, Pierre GILORMINI - Physical interpretation of the Mullins softening in a carbon-black filled SBR - Polymer - Vol. 55, p.4942-4947 - 2014 


\title{
Physical interpretation of the Mullins softening in a carbon-black filled SBR
}

\author{
Rodrigo Diaz, Julie Diani*, Pierre Gilormini \\ Laboratory PIMM, CNRS UMR 8006, Arts et Métiers ParisTech, 151 bd de l'Hôpital, 75013 Paris \\ *Corresponding author: julie.diani@ensam.eu, phone: 33144246192.
}

\begin{abstract}
:
A $40 \mathrm{phr}$ carbon-black filled styrene butadiene rubber has been submitted to several experiments in order to identify the physical damage responsible for the mechanical softening recorded upon first stretch. Damage in the rubber matrix was determined by swelling. The filler structure alteration was monitored by electrical conductivity measurements. Both damages are shown to be of minor importance compared to the substantial mechanical softening undergone by the material. Degradation at the rubber-filler interface may be recovered by exposing the material at high temperatures in vacuo. The chain mobility in such storage conditions promotes free chain adsorption at the filler surface. The existence of a layer of polymer whose movements are hindered adds to the filler reinforcement and its desorption creates Mullins softening.
\end{abstract}

Keywords: Mullins softening, Carbon-black filler, Rubber

\section{Introduction}

When comparing the stress-stretch responses of filled and unfilled rubbers, filled rubbers evidence substantial softening, upon first stretch, known as the Mullins effect (Fig. 1). From a mechanical point of view, the phenomenon is well known. An activation criterion has been established [1] and various constitutive models have been suggested (See references within [2,3]). From a physical point of view, various interpretations have been given [2], which may be arranged in three categories,

- Damage within the rubber matrix: Appearance of cavities, chain scission, disentanglement, change of the number of chemical crosslinks

- Filler network alteration: Filler aggregate or agglomerate fracture, rupture of the carbon-black network (loss of percolation) 
- Rubber-filler interface change: Molecule slips, desorption/adsorption, bond breakage at the filler surface

The present study aims at understanding which physical changes within the material are responsible for the mechanical softening.

Recent experiments measuring the macroscopic volume change during cyclic uniaxial tension [4] have shown that while vacuoles form upon the first stretch, they do not reopen during the subsequent loadings and therefore the mechanical softening cannot be explained by the presence of voids. This result has been corroborated by other studies cited in [4]. Assuming that the material softening is due to damage within the rubber matrix, the average molecular weight of the network chains, characterized by swelling tests, should increase significantly. Yet, according to $[5,6]$ rather small changes are observed by swelling. Electrical conductivity experiments [7] have shown the fracture of the filler network upon mechanical stretching. Nonetheless, while the Mullins softening is strongly anisotropic [8], the electrical anisotropy is rather small, and [7] suggest that while concomitant the network alteration is not the cause of the Mullins softening. In filled rubbers, macromolecular chains become attached to fillers creating physical crosslinks. Various authors (see in [2]) suggest that the Mullins effect results from molecule slippage and detachment at the filler surface. Experimental results from swelling tests show that the drop in physical crosslinks is not significant enough to explain the Mullins softening. As a consequence, in order to understand how the degradation of the rubber-filler interface may have such a drastic impact on the mechanical response of the filled rubbers, another explanation must be taken into account. Actually, the micromechanics analysis of the linear viscoelasticity of carbon-black filled rubbers is in favor of the existence of a layer at the rubber-filler interface significantly stiffer than the rubber matrix due to restrained mobility [9]. A degradation of this layer, by desorption for instance, may have a significant impact on the material stiffness. Moreover, Luo et al. [10] noticed, thanks to NMR observations, that when heated at $80^{\circ} \mathrm{C}$, free chains adsorbed at the carbon-black aggregates surface, which could explain the Mullins recovery at high temperature in vacuo [2].

In order to re-examine the latter theories, a carbon-filled styrene butadiene rubber has been submitted to mechanical tests, swelling tests for the rubber matrix characterization, and conductivity tests for identifying the fracture of the filler network structure. Pre-stretched and virgin samples have also been stored at $80^{\circ} \mathrm{C}$ in vacuo and at $-18^{\circ} \mathrm{C}$ in a freezer before subsequent mechanical tests in order to better understand the physical properties linked to a possible Mullins recovery. 

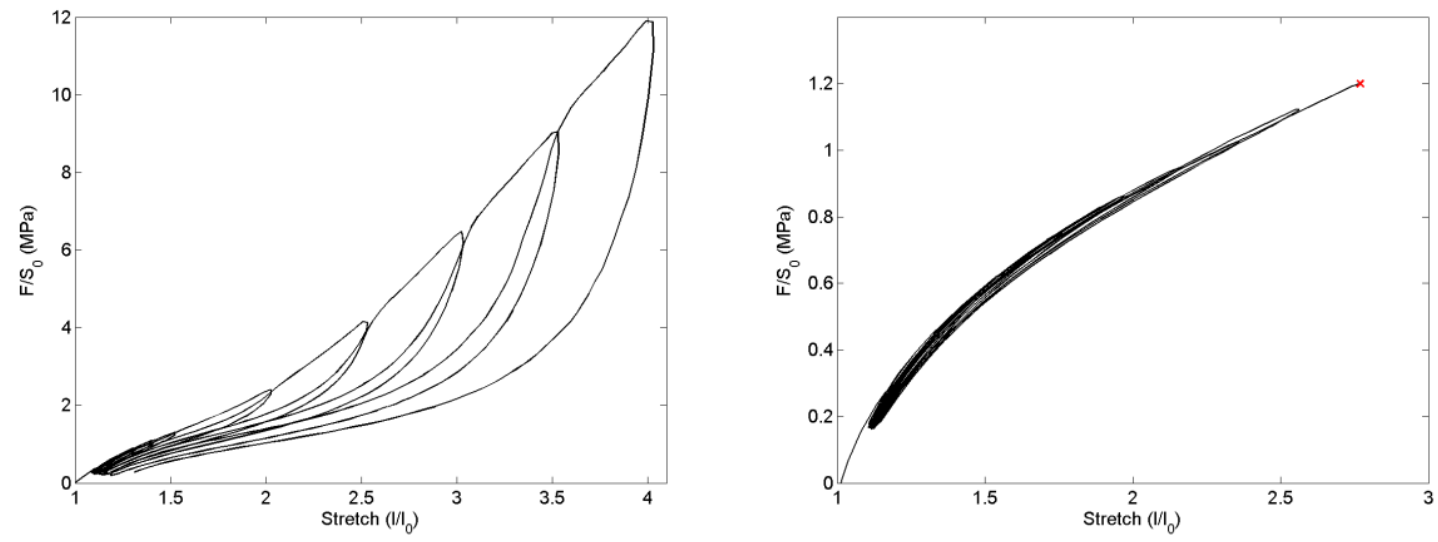

Fig. 1. Stress-stretch response to cyclic uniaxial tension loadings of $40 \mathrm{phr}$ carbon-black filled SBR exhibiting substantial Mullins softening (left) and the unfilled SBR exhibiting no Mullins softening (right).

2. Materials and experiments

\subsection{Materials}

A styrene butadiene rubber (SBR) gum, random copolymer with $15 \%$ mole fraction of styrene with a molecular mass of $120 \mathrm{~g} / \mathrm{mol}$ and a density of $0.94 \mathrm{~g} / \mathrm{cm}^{3}$ filled with $40 \mathrm{phr}$ of N347 carbon-black is considered. The material was manufactured by Michelin into plates of $2.5 \mathrm{~mm}$ thickness. Table 1 lists its composition.

\section{Table 1}

Material composition

\begin{tabular}{ll}
\hline Ingredient & SBR + CB \\
\hline SBR & 100 \\
Carbon-black (N347) & 40 \\
Antioxidant (6PPD) & 1.9 \\
Stearic acid & 2.0 \\
Zinc oxide & 2.5 \\
Accelerator (CBS) & 1.6 \\
Sulfur & 1.6 \\
\hline
\end{tabular}




\subsection{Experiments}

\subsubsection{Uniaxial tension test}

Uniaxial tension tests were performed on an Instron 5881 tensile testing machine at a constant crosshead speed of $10 \mathrm{~mm} / \mathrm{min}$. Local strain was measured by a video extensometer and force was acquired with a $1 \mathrm{kN}$ load cell.

Monotonous tests were performed to pre-stretch the material. For this purpose, rectangular specimens of $40 \mathrm{~mm}$ length and $10 \mathrm{~mm}$ width or dumbbell-shape specimens of $20 \mathrm{~mm}$ working length and $4 \mathrm{~mm}$ width were used according to the geometry requirements for the following tests.

To monitor the Mullins softening, cyclic tests with increasing the maximum strain at each cycle were performed on dumbbell-shape specimen of $20 \mathrm{~mm}$ working length and $4 \mathrm{~mm}$ width.

\subsubsection{Dynamic mechanical test}

Dynamic mechanical tests were performed in uniaxial tension using a DMA Q800 from TA Instruments. Temperature sweeps from $-75{ }^{\circ} \mathrm{C}$ to $40{ }^{\circ} \mathrm{C}$ at $2{ }^{\circ} \mathrm{C} / \mathrm{min}$ and $0.1 \%$ strain were applied on rectangular samples of $30 \mathrm{~mm}$ length and $5 \mathrm{~mm}$ width. For each material characterization, at least three samples were tested. This test provides information on the mechanical behavior of the material not only in the rubbery state but also in the glassy state and through the glass transition. While the Mullins softening is usually exclusively characterized in the rubbery state, this test provides original results on the impact of the Mullins softening on the material properties in the glassy state.

\subsubsection{Swelling characterization}

The average molecular weight of the network chains between crosslinks in rubbers may be determined by swelling tests. According to the rubber elasticity theory, the latter parameter relates directly to the Young modulus of the rubber gum. Therefore, swelling tests may be of interest to assess possible changes within the matrix due to the Mullins effect and resulting on a change of average molecular weight. Virgin and pre-stretched samples may be submitted to swelling tests for comparison.

According to the Flory-Rehner relationship [11], the molecular weight depends on the polymer density, the functionality of crosslinks, the volume fraction of rubber in the swollen samples $\left(v_{r}\right)$ and the interaction parameter between the polymer and the solvent. When comparing virgin and pre-stretched samples, the only changing parameter is the volume fraction of rubber that is measured by swelling. 
Therefore, this quantity is measured according to the following procedure. Dry material samples were immersed in pure toluene in sealed container at room temperature until swelling equilibrium was reached. The weights of the swollen samples $\left(M_{S}\right)$ were immediately measured. Finally, samples were dried and weighted $\left(M_{d}\right)$ a last time. The volume fraction of rubber gum within the filled SBR may be calculated using the following equation [12]:

$$
r=\frac{\frac{\left(M_{d}-M_{C B}\right)}{d}}{\frac{M_{d}-M_{C B}}{d}+\frac{M_{S}-M_{d}}{d_{t}}}
$$

with $d=0.94 \mathrm{~g} / \mathrm{cm}^{3}$ the SBR gum mass density, $d_{t}=0.867 \mathrm{~g} / \mathrm{cm}^{3}$ the toluene mass density and $M_{C B}$ the mass of the carbon-black within the samples, which is given by the relation $M_{C B}=0.2674 M_{d}$ thanks to the material composition in mass listed in Table 1. Equation (1) accounts for the volume fraction of fillers, which as rigid particles reduce the sample swelling. This simple correction may be insufficient for quantitative estimates of the degree of crosslinking, since the presence of rigid particles also restrained the polymer swelling at the filler-rubber interface [13]. Nonetheless, Equation (1) allows comparing the swellings of the virgin and the pre-stretched filled materials in order to detect the impact of pre-stretching on the polymer network.

Note that in order to estimate the possible damage during the swelling tests, due to the local state of tension [13] induced by the presence of the carbon-black fillers, some of the virgin samples were uniaxially tested after swelling and drying. They showed the same mechanical behavior as the virgin samples that were not submitted to swelling.

\subsubsection{Electrical resistivity}

Measurements of resistivity were carried out with a four-point contact method also known as the Kelvin method, which is illustrated in Fig. 2. The battery is used to apply an arbitrary potential difference of 19 $V$ within the circuit. The ammeter measures the current $I$ through the circuit and the voltage recorder monitors the potential difference $V$ that depends on the rubber resistance. The material resistivity is calculated using the Ohm's law:

$$
\rho=\frac{V}{I} \frac{A}{l}
$$

with $l$ being the fixed distance between the points measuring the voltage $V$ and $A$ the sample crosssection area. Note that the Ohm's law was checked on the material by varying the arbitrary applied 
potential difference and verifying the linear relationship between $V$ and $I$. Current intensity was measurable above $0.1 \mu \mathrm{A}$, below this value the material is considered as not conductive.

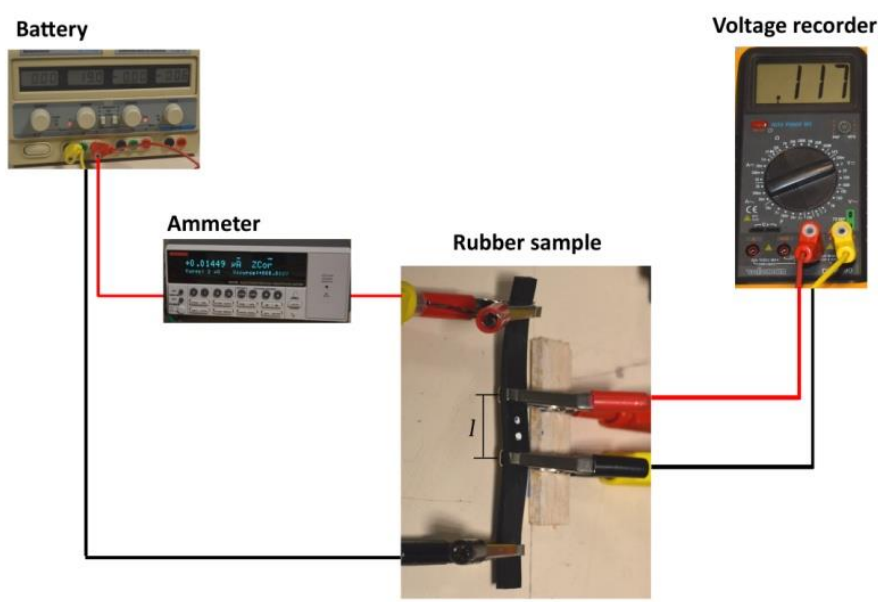

Fig. 2. The four-point contact method used for electrical conductivity.

The amount of fillers (40 phr) within the carbon-black filled SBR was chosen in order to experience Mullins effect and to measure electrical conductivity $(1 / \rho)$. Actually, Fig. 3 shows that the amount $40 \mathrm{phr}$ of carbon-black within this SBR stands for the percolation threshold measurable by our instruments.

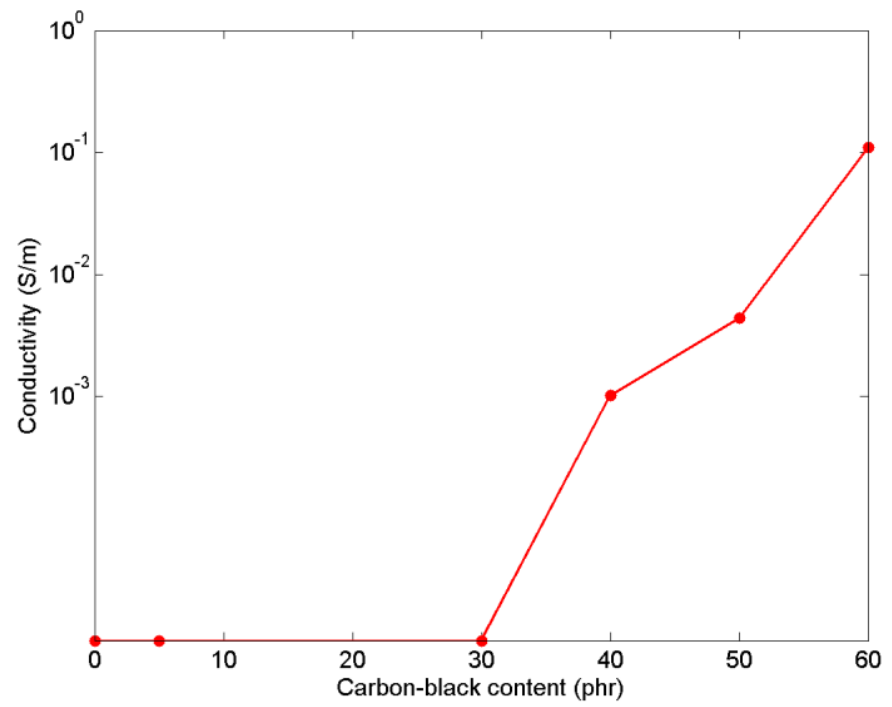

Fig. 3. Initial conductivity of the SBR according to the amount of carbon-black fillers added to the gum 


\section{Results and Discussion}

\subsection{Damage in the rubber matrix}

Such damage as chain breakage, disentanglement, decrease of the number of crosslinks may be checked by swelling tests. The mass of solvent absorbed by the rubber matrix provides access to the volume fraction of swollen rubber that allows calculating the chain average molecular weight. The mechanical properties of the rubber matrix are inversely proportional to the molecular weight. Table 2 presents the volume fraction of swollen rubber measured for virgin samples and samples uniaxially pre-strained to $300 \%$. Three samples were tested for both states. Results are very reproducible. The volume fraction of swollen rubber is slightly smaller for the pre-stretched samples. Considering the possible values of the rubber-solvent interaction coefficient, which varies between 0.31 and 0.446 according to [12], the change of the volume fraction of swollen rubber leads to an increase of molecular weight of approximately $2 \%$ that induces a decrease of modulus of $1 \%$ for the pre-stretched samples. This result is in accordance with results from [5]. Swelling tests completed on virgin and pre-stretched samples of unfilled SBR evidence similar rubber matrix damage whereas the unfilled SBR does not show any Mullins softening (Fig. 1). As a consequence, while some damage happens within the rubber matrix upon stretching, it is not significant enough to cause the Mullins softening. It is interesting to note that this test also shows the change of the number of physical crosslinks, since it does not discriminate chemical crosslinks from physical crosslinks. Therefore, the possible breakage of physical crosslinks is not affecting significantly the average weight of the macromolecular chains.

Finally, note that unlike [14], swelling pre-stretched samples did not produce any recovery of the Mullins effect.

\section{Table 2}

Volume fraction of swollen rubber in the filled SBR measured by toluene swelling

\begin{tabular}{llllll}
\hline Samples \# & 1 & 2 & 3 & Mean & Standard deviation \\
\hline Virgin & 0.2497 & 0.2493 & 0.2487 & 0.2492 & $5.110^{-4}$ \\
$300 \%$ uniaxial pre-srain & 0.2474 & 0.2463 & 0.2477 & 0.2471 & $7.410^{-4}$ \\
\hline
\end{tabular}




\subsection{Effect of stretching on the filler network}

Carbon-black confers electrical conductivity to rubber gum preventing electromagnetic interference and favoring antistatic applications. Once the percolation threshold is reached, electrical conductivity increases drastically as observed in Fig. 3 or in [15]. Upon stretching, the percolation path degrades $[7,15]$. This may be observed by measuring the material resistivity after loading-unloading cycles. Fig. 4 shows the material resistivity after releasing the applied stretch, with respect to the maximum stretch applied. The resistivity increases linearly with the maximum stretch undergone by the material. Therefore, the Mullins softening and the drop of conductivity are concomitant. Nonetheless, according to [7] the carbon-black structure breakdown has a strong impact on the material resistivity but much less on the mechanical behavior. Their conclusion is supported by two experimental results; first Mullins softening induces mechanical anisotropy while the material resistivity is barely anisotropic, second during subsequent mechanical cycling the material resistivity keeps increasing while the mechanical behavior hardly evolves.

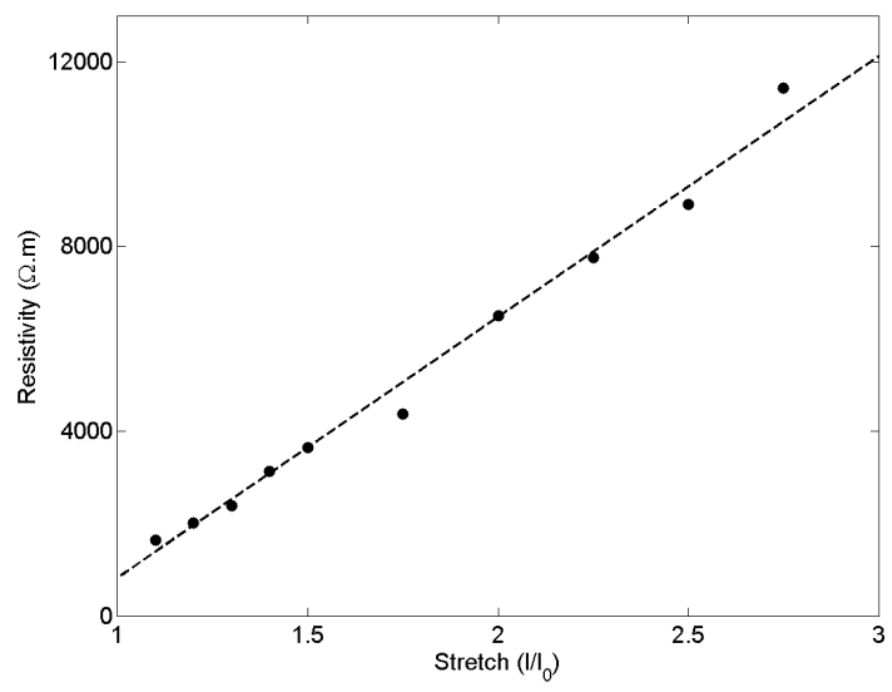

Fig. 4. Material resistivity according to the maximum stretch uniaxially applied

In order to further investigate the relationship between the structure of the filler network and the material mechanical behavior, samples pre-stretched to $2.5\left(150 \%\right.$ strain) have been stored at $-18^{\circ} \mathrm{C}$ in a freezer and at $80^{\circ} \mathrm{C}$ in vacuo before carrying out resistivity tests. It is known that when stored at $-18{ }^{\circ} \mathrm{C}$, the material structure is frozen and the material does not recover from the Mullins softening. To the contrary, when stored at $80{ }^{\circ} \mathrm{C}$ in vacuo, the material recovers from the Mullins softening [2]. Fig. 5 illustrates the effect of the 3-day storage on the mechanical behavior. As expected, no Mullins recovery 
is observed for the sample stored in the freezer. More interestingly, the sample exposed to heat shows complete recovery of the Mullins softening and significant stiffening. Conductivity tests run on the sample after storage are presented in Fig. 6 in terms of normalized current intensity with respect to storage duration. The conductivity of both pre-stretched samples has been significantly altered by the mechanical loading and is not recovered after three days even when stored at high temperatures. Therefore, while the Mullins softening is completely recovered, the material conductivity remains low indicating that the alteration of the filler network is not recovered. This result adds credit to the conclusions of [7]: while concomitant, the filler network alteration is not causing the Mullins softening. In order to better understand the non recovery of the material conductivity, a virgin sample has been stored at $80{ }^{\circ} \mathrm{C}$ in the thermal chamber during three days. Fig. 6 shows that the virgin sample conductivity is also negatively affected by the heating storage. The latter result is rather surprising since heating a carbon-black filled rubber is expected to increase its conductivity [15]. It is believed that the molecular mobility enhanced by the raise of temperature has a negative impact on the material conductivity in this specific case because the material is very close to the percolation threshold. Actually, identical storage conditions applied to the same SBR filled with 50 and $60 \mathrm{phr}$ of carbon-black and previously submitted to similar pre-stretching show partial recovery of the material conductivity and complete Mullins softening recovery.

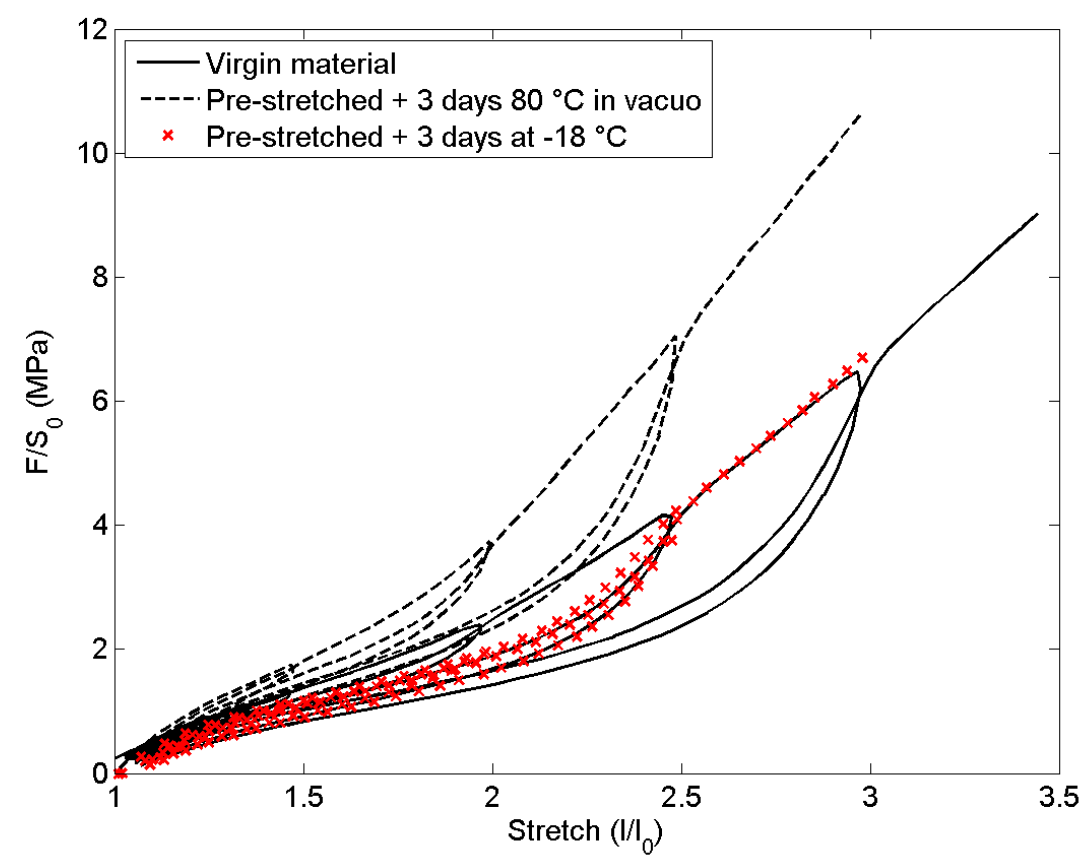

Fig. 5. Effect on the Mullins softening recovery of the storage of samples uniaxially pre-strained to $150 \%$. 


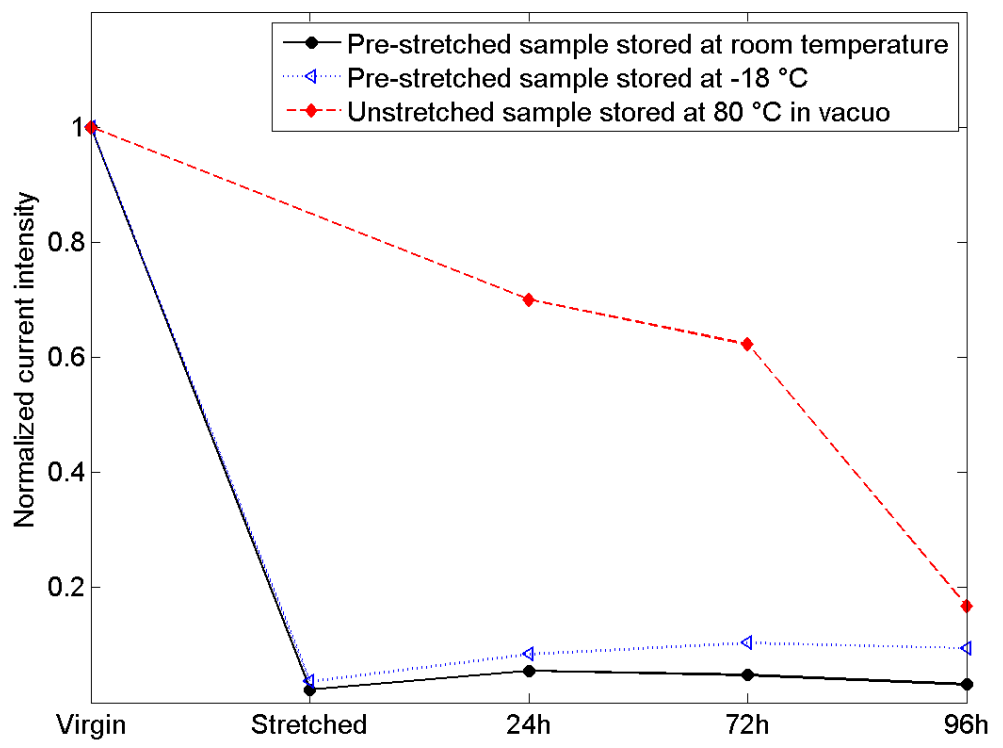

Fig. 6. Conductivity evolution of the SBR after stretching to 2.5 (150\% strain) or not and according to the storage conditions at room temperature, at $-18{ }^{\circ} \mathrm{C}$ in a freezer or at $80^{\circ} \mathrm{C}$ in vacuo.

The resistivity measures evidence an alteration of the network structure after loading. If this alteration has an impact on the material mechanical behavior, it might also show at low temperatures when the material is in the glassy state. In order to test this assumption, uniaxial tension dynamic mechanical analysis tests were run on virgin samples and on samples pre-strained at $300 \%$ in the direction of the dynamic loading. Fig. 7 presents the resulting storage modulus and the damping factor with respect to temperature. The storage modulus shows a significant drop at high temperatures confirming the Mullins softening. At low temperatures, in the glassy state, both virgin and pre-stretched samples exhibit similar stiffnesses. Therefore, the filler structure alteration recorded by electrical conductivity measurements does not seem to affect its reinforcing properties. 

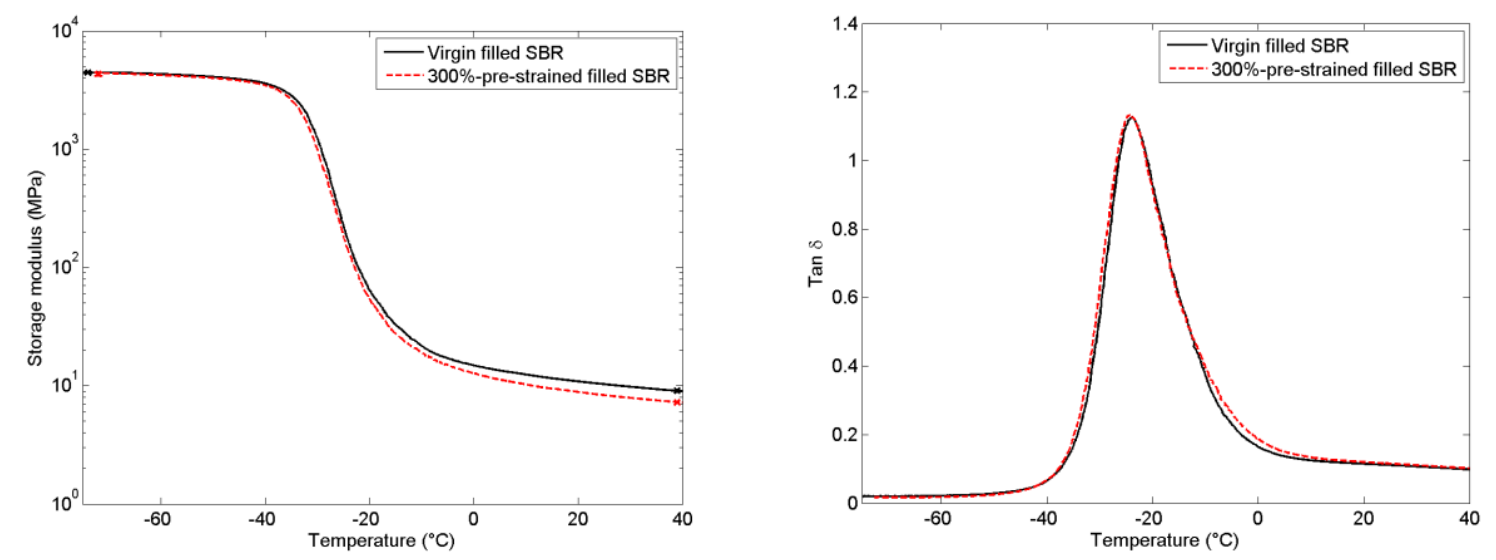

Fig. 7. Impact of the Mullins softening on the material linear viscoelasticity through the glass transition.

\subsection{Damage at the rubber-filler interface}

Since damage within the rubber matrix and of the filler network structure cannot explain the significant softening witnessed upon first stretch, the degradation of the rubber-filler interface remains a possible explanation. [16] and [17] attributed the Mullins softening to breakage and detachment of the rubber chains from the fillers. [18] related it to chain slippage at the filler interface. [19] suggested a variant of [17] macromolecular theory interpreting the Mullins softening by both chain breakage and slippage at the filler surface. Some authors $[20,21]$ are inclined to believe that a layer of hindered polymer exists at the filler surface. The restrained mobility of this layer explains the filler reinforcement [9], and its degradation may explain the Mullins softening. While several authors $[7,22]$ adhere to the rubber-filler interface degradation as the main source of the Mullins softening, the experimental proof is still missing. Modifying the filler interface by adding adhesion agent modifies the filler-rubber interactions but also frequently induces changes in the filler microstructure parameters such as dispersion, cluster size... According to [10], heating a carbon-black filled SBR at $80{ }^{\circ} \mathrm{C}$ increases its chain free motion, boosting adsorption at the filler surface. Therefore, virgin samples were exposed to heating in vacuo at various temperatures during three days. Then, cyclic uniaxial tension tests were applied to these samples. Fig. 8 shows that once heated above a certain temperature, the material is significantly stiffened. In order to discard the interpretation of a possible post chemical reticulation, the unfilled rubber manufactured according to the same process as the filled rubber was also exposed to $80{ }^{\circ} \mathrm{C}$ during three days and submitted to cyclic uniaxial testing. The heated unfilled SBR exhibited the same behavior as the virgin unfilled SBR. Consequently, heating the sample at $80{ }^{\circ} \mathrm{C}$ is believed to make possible the adsorption of 
the rubber at the filler interface. The layer of rubber adsorbed on the filler adds to the material reinforcement and allows Mullins recovery. Moreover, it was noticed that the behavior of the sample pre-strained to $300 \%$ and stored during 3 days at $80{ }^{\circ} \mathrm{C}$ is similar to the behavior of the virgin sample stored during three days at $80^{\circ} \mathrm{C}$, demonstrating the reversibility the Mullins softening.

This physical interpretation of the Mullins softening is consistent with the DMA results (Fig. 7) showing no effect of the Mullins softening on the mechanical behavior of the material in the glassy state. The impact of the polymer layer bonded to the fillers should only read in the rubbery state and within the glass transition, and not in the glassy state. In the latter state, the mobility of the entire rubber network is restrained and the difference of mechanical behavior between the bonded layer and the rubber matrix should be negligible, therefore its damage should not read.

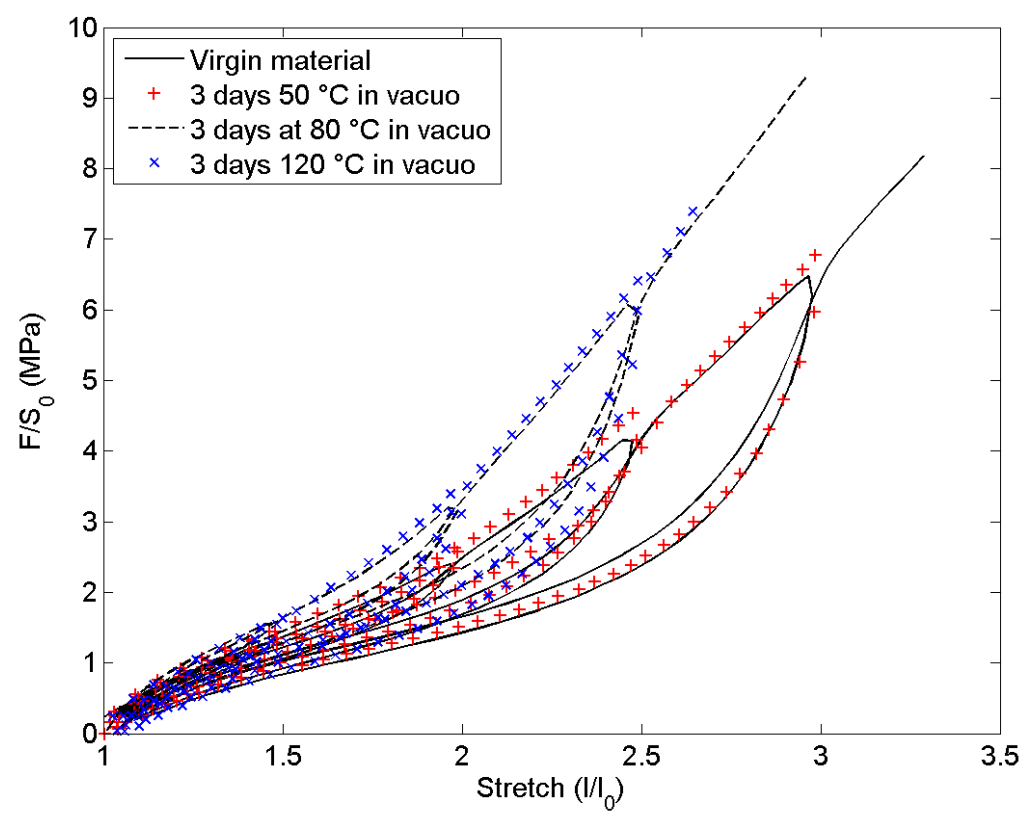

Fig. 8. Effect of heating the virgin material on its stress-stretch response.

Finally, upon stretching, desorption is likely to happen first at the pole of the filler that are aligned with the direction of stretching, inducing non isotropic damage. Therefore, the proposed physical interpretation is compatible with Mullins softening induced anisotropy. 


\section{Conclusion}

A 40 phr carbon-black filled SBR experiencing substantial Mullins softening was submitted to mechanical tests, swelling tests, measures of resistivity in order to understand the physical damage causing the mechanical softening.

Once the Mullins softening occurred due to uniaxial tension, the significance of the damage within the rubber matrix was explored by swelling tests. It was observed that the increase of the average molecular weight of the chains was minor and could not lead to a substantial drop of the material Young modulus. Along with the Mullins softening, breakage of the filler structure was detected by conductivity measurements. While concomitant with the Mullins softening, the alteration of the filler network is not recovered by heating whereas the Mullins softening is. Therefore, the filler network alteration registered by electrical conductivity measurements does not result in significant mechanical softening for the filled rubber. In order to study the impact of the changes at the rubber-filler interface, samples were heated in vacuo. Actually, heating samples in vacuo increases the molecular mobility without risking aging, and free chains adsorb on the filler surface, creating stronger filler-rubber interactions. Storage of virgin and pre-stretched samples at $80{ }^{\circ} \mathrm{C}$ in vacuo increased the filler reinforcement and induced Mullins recovery. Therefore, the layer of bonded rubber at the filler-rubber interface is believed to play a key role in the stiffness and the Mullins softening of the carbon-black filled SBR. The Mullins softening observed upon first stretch is believed to be due to desorption of chains at the filler surface.

Acknowledgement:

The author would like to thank Michelin for providing the materials.

References

[1] Y. Merckel, M. Brieu, J. Diani. A Mullins softening criterion for general loading conditions. J Mech Phys Solids, 60 (2012) 1257-1264.

[2] J. Diani, B. Fayolle, P. Gilormini. A review on the Mullins effect. Eur Polym J, 45 (2009) 601-612.

[3] G. Machado, G. Chagnon, D. Favier. Theory and identification of a constitutive model of induced anisotropy by the Mullins effect. J Mech Phys Solids, 63 (2014) 29-39. 
[4] J. de Crevoisier, G. besnard, Y. Merckel, H. Zhang, F. Vion-Loisel, J. Caillard, D. Berghezan, C. Creton, J. Diani, M. Brieu, F. Hild, S. Roux. Volume changes in a filled elastomer studied via digital image correlation. Polym Testing, 31 (2012) 663-670.

[5] E.M. Dannenberg, J.J. Brenan. Strain-energy as a criterion for stress softening in carbon-black-filled vulcanizates Rubber Chem Tehcnol, 39 (1965), 597-608.

[6] G. Kraus, C.W. Childers, K.W. Rollman. Stress softening in carbon black reinforced vulcanizates. Strain rate and temperature effect. J Appl Polym Sci, 10 (1966) 229-240.

[7] K. Yamaguchi, J.J.C. Busfield, A.G. Thomas. Electrical and mechanical behavior of filled elastomers. I. The effect of strain. J. Polym Sci: Part B: Polym Phys, 41 (2003) 2079-2089.

[8] L. Mullins. Effect of stretching on the properties of rubber. J. Rubber Res, 16 (1948) 275-282.

[9] J. Diani, P. Gilormini, Y. Merckel, F. Vion-Loisel. Micromechanical modeling of the linear viscoelasticity of carbon-black filled styrene butadiene rubbers: The role of the filler-rubber interphase. Mech Mater, 59 (2013) 65-72.

[10] H. Luo, M. Kluppel, H. Schneider. Study of filled SBR elastomers using NMR and mechanical measurements. Macromolecules 37 (2004) 8000-8009.

[11] P.J. Flory, J. Rehner. Statistical mechanics of crosslinked polymer networks. II Swelling. J Chem Phys, 11 (1943) 521-526.

[12] A.J. Marzocca. Evaluation of the polymer-solvent interaction parameter $\chi$ for the system cured styrene butadiene rubber and toluene. Eur Polymer J, 43 (2007), 2682-2689.

[13] T. Kotani, S.S. Sternstein. Birefringence analysis of inhomogeneous swelling in filled elastomers. Springer US, 1971.

[14] J.A.C. Harwood, A.R. Payne. Stress softening in natural rubber vulcanizates. IV. Unfilled vulcanizates. J Appl Polymer Sci, 10 (1966) 1203-1211.

[15] A.I. Medalia. Electrical conduction in carbon black composites. Rubber Chem Technol, 59 (1986) 432-454.

[16] A.F. Blanchard, D. Parkinson. Breakage of carbon-rubber networks by applide stress. Ind Eng Chem, 44 (1952) 799-812.

[17] F. Bueche. Molecular basis for the Mullins effect. J Appl Polym Sci, 4 (1960) 107-114. 
[18] R. Houwink. Slipping of molecules during the deformation of reinforced rubber. Rubber Chem Technol, 29 (1956) 888-893.

[19] F. Clément, L. Bokobza, L. Monnerie. On the Mullins effect in silica-filled polydimethylsiloxane networks. Rubber Chem Technol, 74 (2001) 847-870.

[20] M.P. Wagner. Reinforcing silicas and silicates. Rubber Chem Technol, 49 (1976) 703-774.

[21] L. Chazeau, C. Gauthier, J.M Chenal. Mechanical properties of rubber nanocomposites: How, why...and then ? Rubber nanocomposites: Preparation, properties and applications. John Wiley and Sons, 2010.

[22] L. Bokobza. New Developments in rubber reinforcement. KGK - Kautschuk Gummi Kunststoffe, 0102 (2009) 23-27. 